case of chemical engineering training, the description of which in Europe can scarcely be taken to apply to Great Britain.

In Part 1 the authors discuss the factors which tend to give American manufacturers an advantage over corresponding firms in Europe. Some of these are as follows: more chemical engineers; superior natural resources; larger home market; stronger internal competition; more vigorous sales methods ; greater interest in new processes, products and materials ; breaking down of development projects into simple units each dealt with by specialists greater use of sub-contractors ; more standardization, internal and external ; greater readiness of firms to publish process details; availability of much empirical information; superior methods of transport and storage; and more instrumentation and automatic control.

It seems probable that the rise of the chemical engineer in the United States was originally due to the requirements of the oil industry. His success in this department led naturally to a call for chemical engineers in other branches of the chemical industries, and the cumulative effect was to produce the present large numbers, many of whom are employed successfully in industries not directly connected with chemistry. It is interesting to note, however, a serious decline in the number of new graduates in the subject, the 1953 figure being estimated at only 36 per cent of that for 1950 . This decline is common to other branches of engineering, and a similar trend may be observed in Great Britain.

Many of the advantages listed above are directly dependent on size ; thus the larger the connexions of a specialist firm of equipment makers, the more designs can they hold from which to suit a customer and the more can they spend on research. The report emphasizes the attitude of American manufacturers towards new projects, but fails to mention the deterrents which exist, particularly in Great Britain, in the shape of restrictive regulations, insufficient obsolescence allowance, the risk of loss and, in the event of success, the confiscation by taxation of a large percentage or sometimes nearly the whole of any gains. It is surprising that, in these circumstances, development proceeds at all.

Part 2 contains articles on process instrumentation, catalytic processes, distillation and extraction, heat exchange, special equipment, materials of construction, and transport and storage. With the exception of the first, these savour somewhat of the text-book, although an attempt is made to direct attention to plant and methods which are more commonly used in the United States than in Europe. The twenty-six pages devoted to instrumentation give a clear picture of the extent to which automatic control is used in the United States, and thirty-five diagrams indicate the variety of ways in which it can be applied, as well as showing some of the most modern instruments. It is emphasized that automatic control is not merely a device for saving labour, but that the operation of many modern plants would be impossible without it.

The report itself is highly condensed and it is difficult in a brief notice to give an adequate idea of its contents. Few chemical or plant manufacturers, however, bearing in mind the limitations already referred to and reading the subject-matter in an inquiring rather than in a critical manner, will fail to find ideas or suggestions for which they may be grateful.

\section{ATOMIC ENERGY RESEARCH AT HARWELL}

$T$ HE main research programmes of the Atomic Energy Research Establishment at Harwell since its inception in 1946 to the end of 1951 are described in a fascinating and connected story of the work and problems of the Establishment, which is the first of its kind to be published*. Some of the information has already appeared in scientific journals, but this now account is presented in a fashion which it is hoped will appeal to the more general reader. The subject, however, is far too technical to be appreciated and understood by any but those who have at least a background knowledge of the physics and chemistry of the atom.

Harwell is only a part, but an important central part, of the British atomic energy project. It has been given two main tasks : to conduct research into all aspects of atomic energy, and to advise the production organization and furnish it with the scientific and technical information that it needs. The atomic pile or nuclear reactor is obviously the primary requirement, and the two Harwell piles-'Gleep', the Graphite Low Energy Experimental Pile, which has been in almost continuous operation since August 15, 1947, and 'Bepo', the British Experimental Pile 0, which was started up on July 3, 1948 -have proved invaluable research tools. Full descriptions of these reactors have been published previously, but, for convenience, these are reproduced in an appendix to the volume. Gleep operates at $100 \mathrm{~kW}$., and Bepo, roughly of the same size, operates at $6,000 \mathrm{~kW}$. with air cooling and is mainly concerned with the production of isotopes. These piles have been used to help solve problems in the design of the Windscale production piles, the main function of which is to produce plutonium. This branch of the work is briefly considered in the third of the nine sections into which the volume is divided. Other sections deal with the production and distribution of radioisotopes, perhaps the most widely publicized aspect of the work at Harwell; nuclear reactors and the production of useful power ; particle accelerators, their purpose and the various forms in use at Harwell ; methods of detection of radiation and of protection of atomic energy workers against damage to their health by exposure to radiation; the fundamental research programme involving chemical, physical and metallurgical investigations (engineering, biological and chemical-engineering work will be described in subsequent publications) ; and Harwell's extra-mural relations in the two important categories : collaboration through research and development contracts placed with academic, industrial or government laboratories, and exchange of scientific and technological ideas and information through published work, lectures, training schools and conferences.

To the general reader the sections on radioisotopes and on radiation protection will make most appeal. Present deliveries of isotopes, including those of long life which two years ago could be obtained only from the United States, now number eight hundred a month, and an increasing proportion is now made by air transport to many overseas customers. Various applications of radioisotopes in biological, medical and industrial fields are described. The use of cobalt-60 in place of radium is not so well known as

* Harwell : the British Atomic Energy Research Establishment, 1946-1951. Pp. 128+32 plates, (London: H.M.S.O., 1952.) 68. net. 
it should be, and the recent introduction of radioactive sodium for skin-graft operations is an important advance in plastic surgery. The protective measures taken at Harwell give some indication as to how much protection the general public may be able to get in atomic warfare. The instruments devised for the detection of radiation are sensitive and accurate. The frog-suit and helmet that are worn by those who have to come into contact with highly contaminated areas are somewhat frightening, as shown in the illustration given; but nevertheless it is reassuring in that these workers can be thus protected.

In the sections dealing with fundamental aspects, the research and technical worker will find some interesting information. Among the topics discussed are the study of the unusual erystal structure of uranium, which is orthorhombic at room temperature (some more details have recently been published in an article by Dr. H. M. Finniston in Times Sci. Rev., No. 6 ; winter 1952); the effects of irradiation on the physical properties of crystals and glasses ; neutron diffraction; the splitting of carbon into three, and oxygen into four, helium nuclei by high energy $\mathrm{X}$-rays ; powder metallurgy, principally of beryllium, zirconium and niobium; and research on ceramics.

It would appear that the compilers of this excellent volume intend to encourage the average student of science to extend his knowledge of nuclear physics, and to assist him in this commendable purpose they provide, in an appendix, a list of books suitable for the non-scientist, another list for students up to honours degree standard, and in addition a list of papers on the generation of useful power from nuclear energy. Perhaps further accounts, similar to "Harwell", to bring the story up to date will aim at particular sets of readers, possibly one account for the general public and another more technical one for the student of nuclear energy in its various aspects.

\section{THE WORK OF G. F. FITZGERALD}

A SPECIAL meeting of the Royal Dublin Society A was held on October 30,1951 , to commemorate the centenary of the birth of George Francis FitzGerald (see Nature, 168, 930 ; 1951). A message of greeting was read from the president of the Institution of Electrical Engineers, of the Irish branch of which Prof. FitzGerald was the first chairman. The Physical Society, London, was represented by Prof. K. G. Emeléus, and personal messages of congratulation, received from Sir Edmund Whittaker and from Dr. G. F. C. Searle who remembered FitzGerald personally, were conveyed to the meeting by Prof. F. E. Hackett. Slides and exhibits of some of FitzGerald's models, letters and experiments were shown.

The major part of the meeting was devoted to the reading of five papers dealing with FitzGerald as a man and a scientific worker and with the FitzGeraldLorentz contraction and its relation to the theory of relativity. The text of these papers, together with two illustrations of FitzGerald as he was in 1878 and 1897, is included in the FitzGerald Memorial Number of the Scientific Proceedings of the Royal Dublin Society*. In the first paper, Prof. Hackett discusses the character of FitzGerald as revealed by his letters to Heaviside and gives examples of the several

* Scientific Proceedings of the Royal Dublin Society, 26 (N.S.), No. 1 : Fitzgerald Memorial Number. Pp. $54+3$ plates. (Dublin: brilliant suggestions proposed but not actively pursued by FitzGerald. This is followed by a paper by Prof. H. E. Ives, who, after a brief historical survey of the FitzGerald contraction, derives, using the method of approach of Poincaré's principle of relativity instead of the more usual invariance of the Michelson-Morley experiment, the exact value of the FitzGerald contraction together with the accompanying change of clock frequency perceived by Larmor. Prof. Tves concludes with a brief discussion of the experimental evidence for the contraction and adds some interesting remarks concerning the ether.

Prof. W. H. McCrea discusses some paradoxes of the FitzGerald contraction and their resolution, and Dr. G. J. Whitrow the theories of relativity of Galilean frames with particular reference to E. A. Milne's work. Finally, Prof. J. L. Synge, in a paper entitled "Effects of Acceleration in the Michelson and Morley Experiment", offers an explanation, which be admits may appear fantastic but which is capable of direct experimental test, of D. C. Miller's observations in his 1933 repetition of the MichelsonMorley experiment. The explanation is based on G. H. F. Gardner's theory of the behaviour of a rigid body in accelerated motion. Because of the horizontal position of the interferometer, the original MichelsonMorley experiment is extremely poor as a check on Gardner's theory. An interferometer firmly integrated with the earth and with at least one of the two arms of the interferometer inclined at $45^{\circ}$ to the horizontal is required, and such an instrument, Prof. Synge estimates, even with an arm-length of only $20 \mathrm{~cm}$., compared with Miller's $3,000 \mathrm{~cm}$., would give a fringe shift of a full fringe on rotation about a vertical axis. Reference may be added here to an experiment on these lines made by Prof. R. W. Ditchburn and O. S. Heavens (see Nature, 170, 705 ; 1952).

\section{AMERICAN-ASIAN FLORISTIC RELATIONSHIPS}

$\mathrm{T}$ HE floristic relationship between eastern Asia and eastern North America is the subject of a considerable memoir by Hui-Lin Li (Trans. Amer. Phil. Soc., New Ser., 42, 2, 371; 1952), the subject being one which has interested plant geographers ever since Asa Gray's important paper on the subject in 1840 .

While the present work broadly confirms the basic ideas established one hundred years ago, it reviews and revises the data in the light of modern concepts of taxonomy, nomenclature, plant geography and genetics. There is, in fact, a close floristic relationship between eastern Asia and North America, this being particularly marked in the east. Many genera which are common to, and dominant elements in, the two floristic regions have also a wide, general distribution and are therefore less useful in establishing relationships between the two continental regions. But there are many other less widespread genera which are of particular value in this study. Those genera, common to both continents, which are better developed in western than in eastern North America are considered as primary genera of western North America, whence they have spread eastwards into eastern North America and westwards into adjacent parts of north-eastern Asia. Their range is thus more or less continuous.

Leaving aside the many pan-tropical genera, a number of tropical and subtropical genera are known 